\title{
Natural ventilation reduces high TB transmission risk in traditional homes in rural KwaZulu-Natal, South Africa
}

Melissa Lygizos ${ }^{1 \dagger}$, Sheela V Shenoi ${ }^{2^{*}}$, , Ralph P Brooks ${ }^{2}$, Ambika Bhushan $^{3}$, James CM Brust ${ }^{4}$, Daniel Zelterman ${ }^{5}$, Yanhong Deng ${ }^{5}$, Veronika Northrup ${ }^{5}$, Anthony P Moll ${ }^{6}$ and Gerald H Friedland ${ }^{2}$

\begin{abstract}
Background: Transmission of drug susceptible and drug resistant TB occurs in health care facilities, and community and households settings, particularly in highly prevalent TB and HIV areas. There is a paucity of data regarding factors that may affect TB transmission risk in household settings. We evaluated air exchange and the impact of natural ventilation on estimated TB transmission risk in traditional Zulu homes in rural South Africa.

Methods: We utilized a carbon dioxide decay technique to measure ventilation in air changes per hour (ACH). We evaluated predominant home types to determine factors affecting $\mathrm{ACH}$ and used the Wells-Riley equation to estimate TB transmission risk.

Results: Two hundred eighteen ventilation measurements were taken in 24 traditional homes. All had low ventilation at baseline when windows were closed (mean $A C H=3, S D=3.0$ ), with estimated TB transmission risk of $55.4 \%$ over a ten hour period of exposure to an infectious TB patient. There was significant improvement with opening windows and door, reaching a mean $\mathrm{ACH}$ of $20(\mathrm{SD}=13.1, \mathrm{p}<0.0001)$ resulting in significant decrease in estimated TB transmission risk to 9.6\% ( $p<0.0001)$. Multivariate analysis identified factors predicting $A C H$, including ventilation conditions (windows/doors open) and window to volume ratio. Expanding ventilation increased the odds of achieving $\geq 12 \mathrm{ACH}$ by 60 -fold.

Conclusions: There is high estimated risk of TB transmission in traditional homes of infectious TB patients in rural South Africa. Improving natural ventilation may decrease household TB transmission risk and, combined with other strategies, may enhance TB control efforts.
\end{abstract}

Keywords: Tuberculosis transmission, MDR/XDR TB, Household, South Africa, Infection control, Ventilation

\section{Background}

Airborne infection control is a crucial, often neglected, component of tuberculosis (TB) control [1]. This is particularly true in the era of well-documented primary TB transmission, multidrug-resistant (MDR) and extensively drug-resistant $(\mathrm{XDR}) \mathrm{TB}$ and in resource-limited settings with high prevalence of TB and HIV [1-6].

Tugela Ferry, in KwaZulu-Natal, South Africa, has been greatly impacted by co-epidemics of HIV and drugresistant TB [7]. The initial report of the XDR TB epidemic

\footnotetext{
*Correspondence: sheela.shenoi@yale.edu

${ }^{\dagger}$ Equal contributors

${ }^{2}$ Yale University School of Medicine, AIDS Program, New Haven, CT, USA

Full list of author information is available at the end of the article
}

in Tugela Ferry was attributed, in part, to nosocomial transmission [3]. Modeling studies have subsequently suggested that implementation of combined infection control practices could reduce nosocomial transmission [8], but that an increasing proportion of new XDR TB cases would occur in non-healthcare community settings [9]. TB transmission in community settings and among household contacts of drug susceptible, MDR and XDR TB patients has been receiving increased attention [10-17]. The high prevalence of HIV and drug susceptible and resistant $\mathrm{TB}$ in the context of low socioeconomic status in rural KwaZulu-Natal, provides a large pool of vulnerable household contacts underscoring the need for infection control practices in this setting [3,7,15-19].

\section{Ciomed Central}

(c) 2013 Lygizos et al.; licensee BioMed Central Ltd. This is an Open Access article distributed under the terms of the Creative Commons Attribution License (http://creativecommons.org/licenses/by/2.0), which permits unrestricted use, distribution, and reproduction in any medium, provided the original work is properly cited. 
Strategies and guidelines for infection control, including enhanced ventilation, however, have largely concentrated on healthcare settings $[1,2,20,21]$. Natural ventilation has been shown to be as effective as mechanical ventilation and is particularly attractive in tropical and temperate climates and resource-limited healthcare systems [22]. Previous work in healthcare facilities, but not in household settings, has demonstrated that ventilation, usually measured in air changes per hour $(\mathrm{ACH})$, improves with larger windows and that greater room volume reduces the risk from airborne transmission as estimated using the Wells-Riley model [22-27].

Despite evidence of household and community-based TB transmission - including MDR and XDR TB, little is currently known about air exchange and transmission risk in household or community settings and the potential benefit of ventilation [2]. We evaluated air exchange and the impact of natural ventilation on estimated TB transmission risk in traditional Zulu homes.

\section{Methods \\ Setting}

Ventilation was measured in traditional Zulu homes in Tugela Ferry, an impoverished rural area of approximately 180,000 people with high rates of HIV and drug susceptible and resistant TB. Traditional homes, housing multiple family members, are typically one-room round or box-shaped structures, composed of mud or occasionally plaster walls, wooden doors, and topped with a coneshaped thatch roof or slanted sheet of metal, respectively. Windows, if present, are usually small compared to the size of the home.

\section{Home measurements}

Traditional homes of community members were volunteered and no incentive was given. We recorded the following structural characteristics: building shape and materials; roof materials and thickness; wall thickness and height; wall and ceiling height; room width and volume; door area; windows number, area and position; cross-ventilation; presence, size and type of other ventilation spaces. We defined cross-ventilation as pairs of opposing windows or windows across from the door. In round homes, windows and doors were considered opposing if at an angle of greater than 135 degrees relative to each other.

To account for substantial variability in both the room size and window area amongst homes, a Window-to-Volume Ratio was created, representing the space available for ventilation per volume of air that would need to travel through that space to create an air exchange. This ratio denotes the geometric differences in the conical thatched and flat metal roofed traditional homes.

\section{Environmental measurements}

The following environmental variables were recorded at the initiation of experimentation and hourly throughout the testing session: outside and inside temperature; wind speed at the door, window, and 10 meters from the home where wind flow was unobstructed; relative humidity, and direction of air flow at the door. An AZ-8912 anemometer (Laesent International Co., China) was used to measure all variables with the exception of direction of air flow, which was visualized using the smoke from burning incense sticks.

\section{Ventilation measurements}

A carbon dioxide $\left(\mathrm{CO}_{2}\right)$ concentration-decay technique was used to measure $\mathrm{ACH}$ during late summer through winter [26]. All windows and doors were closed or blocked off, and a baseline $\mathrm{CO}_{2}$ level in parts per million (ppm) was measured. $\mathrm{CO}_{2}$ was released from a pressurized cylinder tank and the concentration was raised to $>8,000$ ppm. A fan mixed the air for about one minute to provide an even concentration of $\mathrm{CO}_{2}$ throughout the room. The ambient $\mathrm{CO}_{2}$ concentration was measured every 30 seconds using a centrally placed analyzer (Bacharach 2815, USA). After the $\mathrm{CO}_{2}$ concentration decay rate with closed door and windows was established, or after approximately 5 minutes, the testing conditions were changed (e.g. windows partially opened); 30-60 seconds were allowed for the changes in ventilation to occur and for a steady-state to be reached, at which time $\mathrm{CO}_{2}$ measurements were retaken; $\mathrm{CO}_{2}$ decay was captured under the following conditions: windows and door closed; windows partially open (door closed); windows fully open (door closed); window and door both open. In each condition $\mathrm{CO}_{2}$ concentration was recorded until it fell to within $200 \mathrm{ppm}$ of the baseline level, concluding that trial. $\mathrm{ACH}$ was calculated as the gradient of the best-fit line through a plot of the natural logarithm of $\mathrm{CO}_{2}$ concentration in ppm plotted against time in hours.

\section{TB risk estimation}

To estimate the risk of $\mathrm{TB}$ infection we used the Wells-Riley equation [ $C=S\left(1-e^{- \text {Iqpt/Q}}\right)$, see legend Table 1] [23,24]. When possible, we used previously established values for variables to facilitate comparison between this and other studies [22]. We designated time of exposure $(t)$ as 10 hours, based on the amount of time a person might spend inside a home overnight in close contact with an infectious TB patient.

\section{Statistical methods}

Descriptive statistics summarized the data; box-plots of $\mathrm{ACH}$ were created for each ventilation condition. 'Windows partially open' and 'windows fully open' were collapsed as there was no statistical difference 
Table $1 \mathrm{ACH}$ and estimated TB risk in predominant home types

\begin{tabular}{|c|c|c|c|c|}
\hline & All homes & Box-shaped, Metal-roofed & Round-shaped, Thatch-roofed & \\
\hline $\mathrm{ACH}$ & Mean (SD) & Mean (SD) & Mean (SD) & p-value \\
\hline Closed & $3(2.9)$ & $3(2.7)$ & $3(3.3)$ & 0.50 \\
\hline Windows Open & $9(7.1)$ & $13(8.1)$ & $5(2.9)$ & 0.01 \\
\hline Windows \& Door & $20(13.1)$ & $27(9.7)$ & $13(12.8)$ & 0.01 \\
\hline \multicolumn{5}{|l|}{ Open } \\
\hline \multicolumn{5}{|c|}{ *TB Risk (10h exposure) } \\
\hline Closed & $55.4(27.8)$ & $58.3(24.7)$ & $52.5(31.5)$ & 0.62 \\
\hline Windows Open & $21.5(14.1)$ & $24.7(18.1)$ & $18(8.4)$ & 0.32 \\
\hline Windows \& Door & $9.6(4.7)$ & $8.9(3.6)$ & $10(5.6)$ & 0.44 \\
\hline Open & & & & \\
\hline
\end{tabular}

SD standard deviation.

Wells Riley equation: $C=S\left(1-e^{-l q p t / Q}\right.$ ) where $C=$ number of new cases, $S=$ number of susceptible individuals, $I=$ number of infectors (presumed to be 1 per household), $\mathrm{q}=$ number of infectious quanta produced per hour per infector (assumed to be 13 based on previous studies) [22], $\mathrm{p}=$ pulmonary ventilation rate of susceptible individuals $(0.6 \mathrm{~m} 3 / \mathrm{h}$, previously established), $\mathrm{t}=$ exposure time of susceptible individuals, $\mathrm{Q}=$ absolute room ventilation (ACH*room volume). The probability of a new case was $\mathrm{C} / \mathrm{S}$.

between these conditions. Evaluations of $\mathrm{ACH}$ and percent TB risk, were performed using mixed effects regression modeling, where each home was treated as a random effect and the repeated nature of the observations within a home was taken into account. $\mathrm{ACH}$ during the closed condition was a covariate. Each predictor of interest was considered in the models independently and significant variables at $\mathrm{p}<0.05$ were then considered in a multivariate model. A variance inflation factor (VIF) was used to assess multicolinearity between variables in the multivariate models: VIF $=1 /\left[1-r^{2}\right]$, where $r$ is bivariate Pearson correlation coefficient; if variables were found to be highly correlated they were not considered together in the multivariate models. Generalized estimating equations (GEE) were utilized to evaluate significant predictors of the probability of achieving $\mathrm{ACH} \geq 12$. Significance was established with alpha $=0.05$ and adjusted for multiple comparisons using the Bonferroni approach. Data were analyzed using SAS 9.2 (Cary, NC).

\section{Ethics statement}

Ethical approval was obtained from University of KwaZulu-Natal, Durban, South Africa, Albert Einstein College of Medicine, Bronx, New York, USA, and Yale University School of Medicine, New Haven, CT, USA. Verbal consent was obtained from household members. The data collected focused exclusively on physical structures and did not pertain to any individual's personal or health information.

\section{Results}

Home, environmental, and ventilation measurements

Two hundred eighteen ventilation measurements were conducted in 24 homes; 12 round-shaped huts with thatched roofs and 12 box-shaped homes with metal roofs (Figure 1). The structural and environmental characteristics of the homes are shown in Table 2 . Compared to box-shaped, round homes had greater room volumes $\left(91.3 \mathrm{~m}^{3}\right.$ vs. $\left.36.6 \mathrm{~m}^{3}, \mathrm{p}<0.001\right)$, were more likely to have cross-ventilation (10 vs. 2 homes,
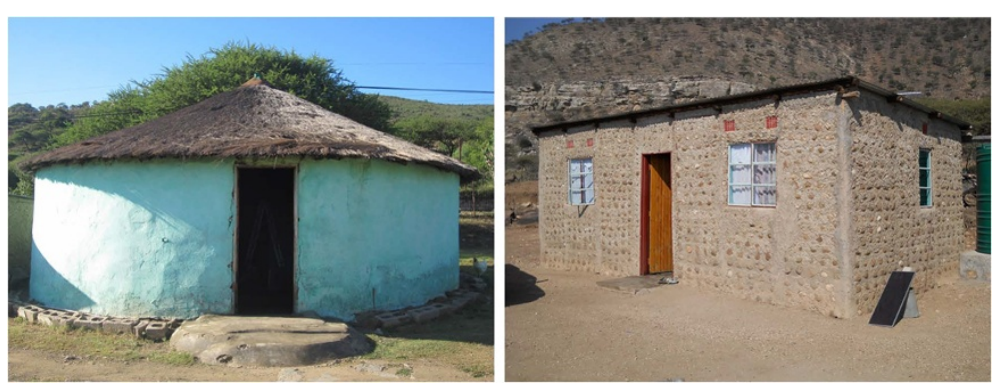

Figure 1 Two predominant types of traditional home construction in Tugela Ferry. A. Round-shaped home with thatched roof B. Box-shaped home with metal roof. 
Table 2 Home Structural Characteristics $(n=24)$

\begin{tabular}{|c|c|}
\hline \multicolumn{2}{|l|}{ Shape } \\
\hline Round & $12(50 \%)$ \\
\hline Box & $12(50 \%)$ \\
\hline \multicolumn{2}{|l|}{ Roof Materials } \\
\hline Thatch & $12(50 \%)$ \\
\hline Metal & $12(50 \%)$ \\
\hline \multicolumn{2}{|l|}{ Number of windows } \\
\hline 0 & $4(17 \%)$ \\
\hline 1 & $6(25 \%)$ \\
\hline 2 & $10(42 \%)$ \\
\hline 3 & $2(8 \%)$ \\
\hline 4 & $2(8 \%)$ \\
\hline \multicolumn{2}{|l|}{ Cross Ventilation } \\
\hline None & $12(50 \%)$ \\
\hline Window-Window & $9(38 \%)$ \\
\hline Window-Door & $6(25 \%)$ \\
\hline \multicolumn{2}{|l|}{ Window Area, mean (SD) } \\
\hline Single window $\left[\mathrm{m}^{2}\right]$ & $0.5(0.2)$ \\
\hline Total window area for home $\left[\mathrm{m}^{2}\right]$ & $0.9(0.7)$ \\
\hline Door Area $\left[\mathrm{m}^{2}\right]$, mean (SD) & $1.5(0.3)$ \\
\hline Floor Area $\left[\mathrm{m}^{2}\right]$, mean (SD) & $22.7(12.4)$ \\
\hline Room Volume $\left[\mathrm{m}^{3}\right]$, mean (SD) & $63.9(38.5)$ \\
\hline \multicolumn{2}{|l|}{ Wind Speed, baseline [m/s], mean (SD) } \\
\hline At door & $0.4(0.4)$ \\
\hline At window & $0.7(0.5)$ \\
\hline Unobstructed & $1.4(0.6)$ \\
\hline \multicolumn{2}{|l|}{ Temperature, baseline $\left[{ }^{\circ} \mathrm{C}\right]$, mean (SD) } \\
\hline Inside & $25.2(3.6)$ \\
\hline Outside & $28.2(5.0)$ \\
\hline Temperature difference (mean) & $3.4(3.0)$ \\
\hline
\end{tabular}

$\mathrm{p}<0.01$ ), but had a smaller Window-to-Room Ratio $\left(8^{*} 10^{-3} \mathrm{~m}^{-1}\right.$ vs. $\left.27^{*} 10^{-3} \mathrm{~m}^{-1}, \mathrm{p}<0.01\right)$. The ambient indoor and outdoor temperatures and the wind speed are shown in Table 2. Air was flowing in through the door in 14 homes $(58 \%)$, out the door in 7 (29\%), and had no clear direction in 3 homes (13\%).

Among all homes, the mean $\mathrm{ACH}$ improved when windows were opened and improved further when windows and door were both opened $(\mathrm{p}<0.0001)$ (Table 1, Figure 2a). Of note, there was no significant difference in $\mathrm{ACH}$ under closed conditions when any extra ventilating spaces, such as vents, remained open or were covered. Although there was no difference in baseline $\mathrm{ACH}$, ventilation was more favorable in box-shaped metal roof homes than in round thatched roof homes as windows and door were opened $(\mathrm{p}=0.01)$ (Table 1$)$.

\section{TB risk estimation}

The estimated risk of TB transmission after ten hours of exposure to an infectious TB patient with windows and door closed was $55.4 \%(\mathrm{SD}=27.8 \%)$. This risk dropped significantly upon opening windows $(21.5 \%, \mathrm{SD}=14.1 \%$, $\mathrm{p}<0.001$ ), and further upon opening windows and door together $(9.6 \%, \mathrm{SD}=4.7, \mathrm{p}<0.001$ ) (Table 1 , Figure $2 \mathrm{~b}$ ). The estimated risk of TB infection increased in parallel to exposure time $(\mathrm{p}<0.001)$ (Figure 3$)$. Despite the differences in $\mathrm{ACH}$, there was no significant difference in estimated TB transmission risk under any condition between the two main home types (Table 1). Notably, the estimated risk with 2 hours of exposure in a closed room approximates that at 24 hours with windows and doors open (Figure 3).

\section{Predictors of $\mathrm{ACH}$}

Univariate analyses identified factors that were significantly associated with ACH (Table 3). Multivariate analysis demonstrated a model (Table 4) in which $\mathrm{ACH}$ was dependent on the ventilation conditions, as $\mathrm{ACH}$ increased from windows closed to windows open to windows and door open, as well as on the Window-to-Volume Ratio (ACH increased by 0.4 for every unit increase in the ratio, $\mathrm{F}$-value $=24.2, \mathrm{p}<0.0001) \quad($ Table 4). The enhanced ventilation increased the odds of achieving a minimum of $12 \mathrm{ACH}$ by 60 -fold (Table 4).

The finding that window-volume ratio is a significant factor may be less helpful for the average community member in our impoverished resource limited setting to implement. A second equally strong model (Table 5) similarly demonstrated that $\mathrm{ACH}$ is dependent on ventilation conditions (windows closed, windows open, windows and door open), but instead of the windowvolume ratio, this model demonstrates that the key factors associated with $\mathrm{ACH}$ are home shape (box-shape vs. round-shape, $\mathrm{F}$-value $=20.3, \mathrm{p}=0.0002$ ) and the number of windows $(\mathrm{F}$-value $=11.1, \mathrm{p}<0.01)$.

\section{Discussion and conclusions}

We measured and evaluated air exchange, estimated TB transmission risk, and the impact of natural ventilation in traditional homes and huts in rural South Africa. We believe that this is the first study to perform such measurements and to quantitate TB transmission risk at the household level in a high prevalence HIV and TB and drug resistant TB rural setting. We found low baseline ventilation and an extremely high estimated risk of TB transmission (9.6-55.4\%) in household settings, where index patients with $\mathrm{TB}$ interact frequently with vulnerable family members and other community members, including those possibly HIV infected in this high prevalence HIV area. We also found and quantitated simple measures in the household setting 

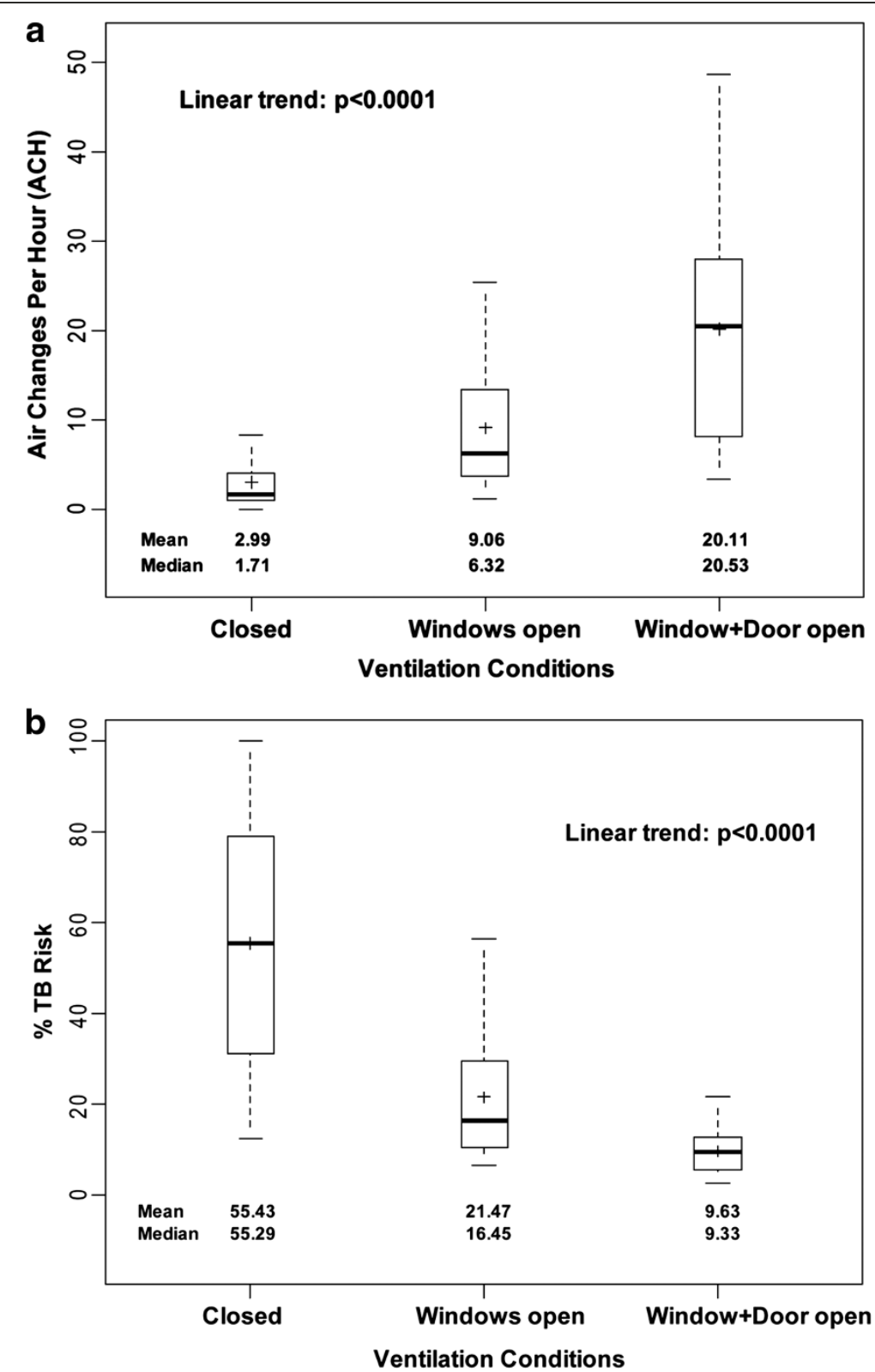

Figure $2 \mathrm{ACH}$ and Estimated TB Risk under different ventilation conditions. Box-plot of ACH and estimated TB risk from the various ventilation conditions tested: (1) baseline with windows and door closed, (2) windows open, and (3) windows and door open. Mean ACH and TB risk for each condition is marked with " + ". Median ACH and TB risk is marked by the solid horizontal line, with the upper and lower ends of the box representing the limits of the interquartile range (IQR). The dotted lines represent the range of values. a. ACH b. Estimated TB Risk.

that could significantly improve ventilation and reduce transmission risk in the household setting.

Studies of TB transmission have focused on health care settings, and evidence based airborne infection control strategies have been developed to reduce transmission in hospitals and clinics. Although there is increasing recognition of $\mathrm{TB}$ transmission occurring in community settings, particularly households, the scientific and public health communities lack evidence to inform infection control strategies in this setting [2,10-17]. The WHO recommendation of $\mathrm{ACH} \geq 12$ is based on estimates in health care settings [1]; there are no clear data to inform recommendations for non health care settings in endemic TB regions [2]. The present study provides important new descriptive information to help understand air exchange and TB transmission risk in the household setting in rural sub-Saharan Africa and also demonstrates that the simple procedure of opening existing windows and doors can significantly reduce TB transmission risk. Though these findings may be intuitive, the provision of quantitative 


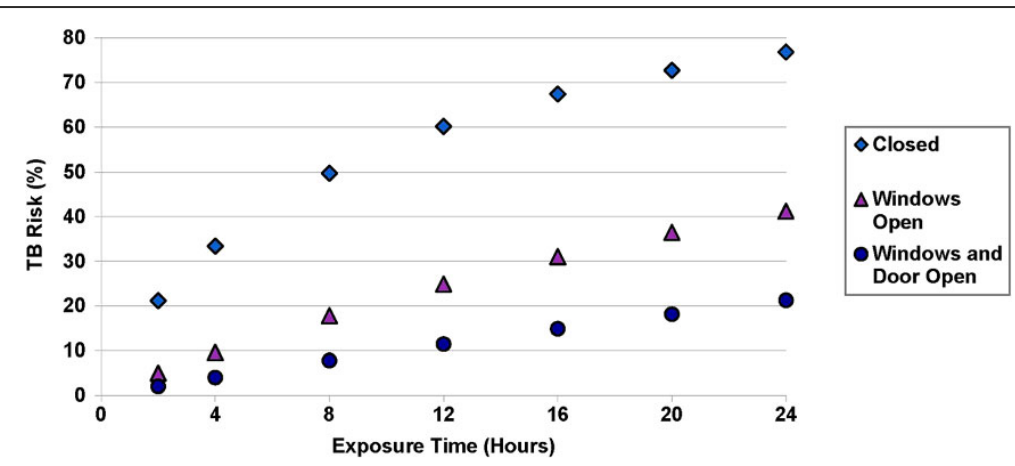

Figure 3 Estimated Risk of TB Infection by Exposure Time. Risk of TB infection after various durations of exposure to an active TB case under different ventilation conditions, as estimated using the Wells-Riley equation. Diamond: windows and door closed; Triangle: windows open; Circle: windows and door open together.

estimates of $\mathrm{ACH}$ and $\mathrm{TB}$ transmission risk can be used to inform patients, communities, programs and future household construction and help spur development and implementation of airborne infection control strategies

Table 3 Univariate analyses identifying factors associated with ACH in traditional Zulu homes

\begin{tabular}{|c|c|c|}
\hline Variables & Coefficient & $\mathrm{p}$ value $(\mathrm{N}=24)$ \\
\hline Height of walls & 11.57 & 0.01 \\
\hline Width of room & -4.57 & 0.02 \\
\hline Floor area & -0.38 & 0.01 \\
\hline Volume of room & -0.12 & 0.02 \\
\hline Surface area of walls & -0.13 & 0.62 \\
\hline Door area & 8.03 & 0.21 \\
\hline Window number & 2.79 & 0.09 \\
\hline Window area & 5.66 & 0.05 \\
\hline Combine area of wind/door & 5.44 & 0.02 \\
\hline Wind speed at door & 4.08 & 0.45 \\
\hline Wind speed 10m & 0.82 & 0.83 \\
\hline House Shape & 9.69 & 0.005 \\
\hline Materials of roof & 10.43 & 0.005 \\
\hline \multicolumn{3}{|l|}{ Metal vs. Thatch } \\
\hline Other ventilation space & -1.80 & 0.75 \\
\hline \multicolumn{3}{|l|}{ Absent vs. Present } \\
\hline Window area/wall surface & 372.65 & 0.0024 \\
\hline Window area/floor area & 145.68 & 0.0001 \\
\hline Window/volume & 414.23 & $<0.0001$ \\
\hline \multicolumn{3}{|l|}{ Temperature } \\
\hline Inside & 0.03 & 0.96 \\
\hline Outside & -0.43 & 0.31 \\
\hline Difference & -1.00 & 0.10 \\
\hline Relative humidity & 0.12 & 0.49 \\
\hline \multicolumn{3}{|l|}{ Smoke direction } \\
\hline In & 5.46 & 0.40 \\
\hline Out & 8.15 & 0.26 \\
\hline
\end{tabular}

suitable for community settings. Ventilation strategies may be a useful adjunctive tool to case finding, rapid diagnostics, improving treatment outcomes, and ART expansion.

Previous studies have shown that the area contributing to ventilation, such as the area of an open window, have an impact on ventilation; even intermittent window opening may significantly improve ventilation and air quality within a room [28]. However, our evaluation also demonstrated the importance of the room volume. Though box-shaped metal roof homes had higher $\mathrm{ACH}$, this was offset by the larger volume of round thatch-roof homes with resultant similar estimated TB transmission risk. Multivariate analyses demonstrated that enhancing the ventilation conditions by opening windows and doors and a greater window/volume ratio were associated with better $\mathrm{ACH}$. In a less technically complex, equally strong model that could be more easily utilized to educate community members, opening doors and windows, box-shaped metal roof homes (compared to round thatched roof), and increased number of windows were associated with improved $\mathrm{ACH}$. Both models suggest that greater opportunities for air flow and increased area available for ventilation are important determinants of

Table 4 Adjusted mixed model analysis associated with improved ACH in traditional Zulu homes

\begin{tabular}{|c|c|c|c|c|}
\hline \multirow[b]{2}{*}{ Variable } & \multicolumn{4}{|c|}{ Model 1} \\
\hline & $\begin{array}{l}\text { Parameter } \\
\text { Estimate (SE) }\end{array}$ & p-value ${ }^{1}$ & $\begin{array}{l}\text { Odds Ratio } \\
(95 \% \mathrm{Cl})\end{array}$ & p-value ${ }^{2}$ \\
\hline $\begin{array}{l}\mathrm{ACH} \text { in closed } \\
\text { condition }\end{array}$ & $1.7(0.5)$ & $<0.01$ & $1.8(1.2,2.7)$ & $<0.01$ \\
\hline \multicolumn{5}{|l|}{ Ventilation Condition } \\
\hline Window Open & $10.9(2.1)$ & $<0.0001$ & $\begin{array}{c}66.6 \\
(5.0,790.8)\end{array}$ & $<0.01$ \\
\hline \multicolumn{5}{|l|}{$\begin{array}{l}\text { Window \& Door } \\
\text { Open }\end{array}$} \\
\hline $\begin{array}{l}\text { Window-Volume } \\
\text { Ratio }\end{array}$ & $0.4(0.02)$ & $<0.0001$ & $1.5(1.1,2.0)$ & $<0.01$ \\
\hline
\end{tabular}

${ }^{1}$ Obtained from mixed effects regression.

${ }^{2}$ Obtained from GEE. 
Table 5 An alternative adjusted mixed model analysis associated with improved $\mathrm{ACH}$

\begin{tabular}{lcc}
\hline & \multicolumn{2}{c}{ Model 2 } \\
\cline { 2 - 3 } Variable & $1.9(0.5)$ & p-value \\
\hline ACH in closed condition & & $<0.01$ \\
Ventilation Condition & $11.5(2.1)$ & $<0.0001$ \\
$\quad$ Window Open & & \\
$\quad$ Window \& Door Open & & $<0.001$ \\
Type of Home & $12.2(2.7)$ & \\
$\quad$ Simple Box & & $<0.01$ \\
$\quad$ Simple Round & $4.8(1.4)$ & \\
Number of windows & &
\end{tabular}

${ }^{1}$ Obtained from mixed effects regression.

$\mathrm{ACH}$ in this setting. Community members may be able to plan renovations or new homes with box-shaped, metal roofs and an increased number of windows.

While previous studies of natural ventilation in healthcare settings have emphasized the direction of air movement, this does not likely have as much consequence in our setting as most homes do not have adjoining rooms into which infectious particles may enter after leaving the room in question. Temperature, wind speed and direction, and humidity were not significant predictors, possibly due to differences in climate.

In our study, the ventilation improved incrementally as the area contributing to ventilation increased, though many homes had only a few small windows, limiting substantial increases. In most homes, only when windows were opened in combination with the door was the WHO recommended $12 \mathrm{ACH}$ threshold reached [1,21]. The full success of this intervention may require increasing the number and/or size of windows and ensuring that windows and doors remain open. Both represent challenges in rural Africa where resources for construction are limited and closing windows and doors at night for safety and/or to reduce insect exposure is common. Information regarding household usage patterns, acceptability of infection control interventions, and barriers to implementation are needed to inform the development and evaluation of more comprehensive behavioral and community-oriented airborne infection control strategies.

We recognize several limitations in this study. First, the two home construction types examined are typical of rural KwaZulu-Natal, South Africa. Thus, the transmission risk data may not be fully applicable in other resource-limited settings, even in sub- Saharan Africa. For example, in another study in an urban township in South Africa use of public transportation appeared to confer great TB transmission risk than in the household setting [12]. We do believe that the data gathered in our study are sufficiently similar to those in other rural settings in sub-Saharan
Africa to have broader relevance. Secondly, natural ventilation is feasible in tropical climates or in temperate climates only during warmer seasons and limited in colder climates. Additionally, though being the best currently available model for TB transmission and one that has been used in similar studies, the Wells-Riley model provides a theoretical, not a true, assessment of risk. The equation utilizes many important factors, but some such as the number of infectious particles produced by a patient; or proximity of the infectious and susceptible individuals to each other, are not taken into account. Furthermore, the equation measures steady exposure over a finite time period, 10 hours in this study, whereas TB transmission risk, in reality, encompasses multiple exposures and may be cumulative, particularly in household settings.

Further work is now needed to apply the information gained from this study on a broader public health level, to develop strategies to reduce TB transmission in this and other rural communities heavily impacted by drug susceptible and drug resistant TB. Although there are economic and logistical barriers, the cost and challenges of airborne infection control neglect should be calculated in the context of missed opportunities for potential prevention of morbidity and mortality and secondary TB transmission.

\section{Competing interests}

The authors declare that they have no competing interests.

\section{Authors' contributions}

ML, SVS, RPB, JCMB, APM, GHF designed the study. ML, RPB, AB performed the experiments. ML, SVS, RPB, AB, DZ, VN, YD, GHF analyzed the data. ML, SVS, RPB, JCMB, VN, APM, GHF wrote the manuscript. All authors read and approved the final manuscript.

\section{Acknowledgments}

We would like to thank: Philanjalo; Drs. Edward Nardell, Paul Jensen, and A. Roderick Escombe for their encouragement and generously sharing their expertise; and Sipho Nsele, Phelelani Buthelezi, Njabulo Malembe, Sibongile Lembethe, Mary Mabogoane, and Eugene Meyer for their contributions to this project.

\section{Funding}

$M L$ received funding from the Doris Duke Charitable Foundation. SVS received funding from Fogarty International Clinical Research Fellowship (R24TW007988), Gilead Foundation, the President's Emergency Plan for AIDS Relief, and the National Institute of Allergy and Infectious Diseases (K23Al089260). JCMB received support from the National Institute of Allergy and Infectious Diseases (K23Al083088) and the Einstein/Montefiore Center for AIDS Research (P30AI051519). AB received support from Charles Howland Foundation. GHF received funding from the Irene Diamond Fund, Gilead Foundation and the President's Emergency Plan for AIDS Relief. DZ, YD, VN were supported by NRCC CTSA UL1 RR024139.

\section{Author details}

'University of Colorado School of Medicine, Aurora, CO, USA. ${ }^{2}$ Yale University School of Medicine, AIDS Program, New Haven, CT, USA. ${ }^{3}$ Harvard University School of Medicine, Boston, MA, USA. ${ }^{4}$ Montefiore Medical Center and Albert Einstein College of Medicine, Bronx, NY, USA. ${ }^{5}$ Center for Analytical Sciences, Yale University School of Public Health, New Haven, CT, USA. ${ }^{6}$ Church of Scotland Hospital, Tugela Ferry, South Africa. 
Received: 27 December 2012 Accepted: 13 June 2013

Published: 1 July 2013

\section{References}

1. World Health Organization: WHO Policy on TB Infection Control in Health-Care Facilities, Congregate Settings, and Households. Geneva; 2009

2. Shenoi SV, Escombe AR, Friedland G: Transmission of Drug-Susceptible and Drug-Resistant Tuberculosis and the Critical Importance of Airborne Infection Control in the Era of HIV Infection and Highly Active Antiretroviral Therapy Rollouts. Clin Infect Dis 2010, 50(S3):S231-S237.

3. Gandhi NR, Moll A, Sturm AW, Pawinski R, Govender T, Lalloo U, Zeller K, Andrews J, Friedland G: Extensively drug-resistant tuberculosis as a cause of death in patients co-infected with tuberculosis and HIV in a rural area of South Africa. Lancet 2006, 368(9547):1575-1580.

4. Andrews J, Gandhi N, Moodley P, Shah N, Bohlken L, Moll A, Pillay M, Friedland G, Sturm A: Exogenous reinfection as a cause of multidrug-resistant and extensively drug-resistant tuberculosis in rural South Africa. $J$ Infect Dis 2008, 198(11):1582-1589.

5. Shenoi SV, Brooks RP, Barbour R, Altice FL, Zelterman D, Moll AP, Master I, van der Merwe TL, Friedland GH: Survival from XDR-TB Is Associated with Modifiable Clinical Characteristics in Rural South Africa. PLoS One 2012, $7(3)$.

6. Zhao Y, Xu S, Wang L, Chin DP, Wang S, Jiang G, Xia H, Zhou Y, Li Q, Ou X, et al: National Survey of Drug-Resistant Tuberculosis in China. N Eng $J$ Med 2012, 366(23):2161-2170.

7. Gandhi N, Shah NS, Andrews J, Vella V, Moll A, Scott M, Weissman D, Marra C, Lalloo U, Friedland G: HIV coinfection in multidrug- and extensively drug-resistant tuberculosis results in high early mortality. Am J Respir Crit Care Med 2010, 181(1):80-86.

8. Basu S, Andrews J, Poolman E, Gandhi N, Shah NS, Moll A, Moodley P, Galvani A, Friedland G: Prevention of nosocomial transmission of extensively drug-resistant tuberculosis in rural South African district hospitals: an epidemiological modelling study. Lancet 2007, 370(9597):1500-1507.

9. Basu S, Friedland G, Medlock J, Andrews J, Shah NS, Gandhi N, Moll A, Moodley P, Sturm AW, Galvani A: Averting epidemics of extensively drug-resistant tuberculosis. Proc Natl Acad Sci USA 2009, 106(18):7672-7677.

10. Middelkoop K, Bekker LG, Myer L, Dawson R, Wood R: Rates of tuberculosis transmission to children and adolescents in a community with a high prevalence of HIV infection among adults. Clin Infect Dis 2008, 47(3):349-355.

11. Johnstone-Robertson SP, Mark D, Morrow C, Middelkoop K, Chiswell M, Aquino LDH, Bekker L-G, Wood R: Social Mixing Patterns Within a South African Township Community: Implications for Respiratory Disease Transmission and Control. Am J Epidemiol 2011, 174(11):1246-1255.

12. Wood R, Racow K, Bekker L-G, Morrow C, Middelkoop K, Mark D, Lawn SD: Indoor Social Networks in a South African Township: Potential Contribution of Location to Tuberculosis Transmission. PLoS One 2012, 7(6):e39246.

13. Whalen CC, Zalwango S, Chiunda A, Malone L, Eisenach K, Joloba M, Boom WH, Mugerwa R: Secondary Attack Rate of Tuberculosis in Urban Households in Kampala. Uganda. PloS one 2011, 6(2):e16137.

14. Shapiro AE, Variava E, Rakgokong MH, Moodley N, Luke B, Salimi S, Chaisson RE, Golub JE NAM: Community-based targeted case-finding for tuberculosis and HIV in household contacts of tuberculosis patients in South Africa. Am J Respir Crit Care Med 2012.

15. Vella V, Racalbuto V, Guerra R, Marra C, Moll A, Mhlanga Z, Maluleke M, Mhlope H, Margot B, Friedland G, et al: Household contact investigation of multidrug-resistant and extensively drug-resistant tuberculosis in a high HIV prevalence setting. Int J Tuberc Lung Dis 2011, 15(9):1170-1175.

16. Becerra MC, Appleton SC, Franke MF, Chalco K, Arteaga F, Bayona J, Murray M, Atwood SS, Mitnick CD: Tuberculosis burden in households of patients with multidrug-resistant and extensively drug-resistant tuberculosis: a retrospective cohort study. Lancet 2011, 377(9760):147-152.

17. Grandjean L, Crossa A, Gilman RH, Herrera C, Bonilla C, Jave O, Cabrera JL, Martin L, Escombe AR, Moore DAJ: Tuberculosis in household contacts of multidrug-resistant tuberculosis patients. Int J Tuberc Lung Dis 2011, 15(9):1164-1169. i.

18. Republic of South Africa Department of Health: National 2009 Antenatal Sentinel HIV \& Syphilis Prevalence Survey in South Africa. Pretoria; 2009.
19. World Health Organization: Guidelines for intensified tuberculosis case-finding and isoniazid preventive therapy for people living with HIV in resource constrained settings. Geneva; 2010

20. Joshi R, Reingold A, Menzies D, Pai M: Tuberculosis among health-care workers in low- and middle-income countries: a systematic review. PLoS Med 2006, 3(12):e494-e494.

21. Jensen $P$, Lambert $L$, lademarco M, Ridzon R: Guidelines for preventing the transmission of Mycobacterium tuberculosis in health-care settings, 2005. Morb Mortal Wkly Rep Recomm Rep 2005, 54(RR-17):1-141.

22. Escombe AR, Oeser C, Gilman R, Navincopa M, Ticona E, Pan W, Martnez C, Chacaltana J, Rodrguez R, Moore DAJ, et al: Natural ventilation for the prevention of airborne contagion. PLoS Med 2007, 4(2):e68-e68.

23. Wells W: Airborne contagion and air hygiene. Cambridge: Harvard University Press; 1955.

24. Riley EC, Murphy G, Riley RL: Airborne spread of measles in a suburban elementary school. Am J Epidemiol 1978, 107(5):421-432.

25. Nardell EA, Keegan J, Cheney SA, Etkind SC: Airborne infection. Theoretical limits of protection achievable by building ventilation. Am Rev Respir Dis 1991, 144(2):302-306.

26. Menzies R, Schwartzman K, Loo V, Pasztor J: Measuring ventilation of patient care areas in hospitals. Description of a new protocol. Am J Respir Crit Care Med 1995, 152(6):1992-1999.

27. Cox H, Escombe R, McDermid C, Mtshemla Y, Spelman T, Azevedo V, London L: Wind-Driven Roof Turbines: A Novel Way to Improve Ventilation for TB Infection Control in Health Facilities. PLoS One 2012, 7(1):e29589.

28. Heiselberg $P$, Perino M: Short-term airing by natural ventilation - implication on IAQ and thermal comfort. Indoor Air 2010, 20(2):126-140.

doi:10.1186/1471-2334-13-300

Cite this article as: Lygizos et al:: Natural ventilation reduces high TB transmission risk in traditional homes in rural KwaZulu-Natal, South Africa. BMC Infectious Diseases 2013 13:300.

\section{Submit your next manuscript to BioMed Central and take full advantage of:}

- Convenient online submission

- Thorough peer review

- No space constraints or color figure charges

- Immediate publication on acceptance

- Inclusion in PubMed, CAS, Scopus and Google Scholar

- Research which is freely available for redistribution

Submit your manuscript at www.biomedcentral.com/submit
C Biomed Central 